\title{
An in vivo comparison of accuracy of two electronic apex locators in determining working length using stainless steel and nickel titanium files
}

This article was published in the following Dove Press journal:

Clinical, Cosmetic and Investigational Dentistry

\author{
Sanjeeb Chaudhary \\ Archana Gharti \\ Bhawana Adhikari \\ Department of Conservative \\ Dentistry and Endodontics, School \\ of Dental Sciences, Chitwan Medical \\ College, Bharatpur, Nepal
}

\begin{abstract}
Purpose: A key factor affecting the success of endodontic treatment is correct determination of root canal working length (WL). The purpose of this in vivo study was to compare the accuracy of Propex II and iPex II electronic apex locator (EAL) in determining the WL under clinical conditions, to that of radiographic working length (RWL) using stainless steel (SS) and nickel-titanium (NiTi) hand files.
\end{abstract}

Patients and methods: Thirty-seven patients, with 60 anterior teeth ( 60 canals) scheduled for endodontic treatment participated in this study after ethical approval. Electronic working length (EWL) was determined by the Propex II and iPex II according to manufacturer's instructions using SS Hand K-files and NiTi Hand files. RWL was determined after EWL determination. The results obtained with each EAL with SS and NiTi files were compared with RWL. Data was analyzed statistically at a significance level of $p<0.05$. Interclass correlation coefficient was calculated.

Results: Statistical analysis revealed no significant difference between the EALs, indicating similar accuracies between them with respect to accuracy in determining the WL $(p>0.05)$. No significant difference was found between the EWL and RWL and between SS and NiTi files for WL determination $(p>0.05)$ as well. The result also displayed a high intraclass correlation coefficient between the RWL and EWL measurement methods.

Conclusion: Under the in vivo clinical conditions of this study, both Propex II and iPex II were similar to the RWL determination technique showing high correlation to RWL. Both are clinically acceptable EAL for WL determination and both SS hand K-file and NiTi file can be used interchangeably without compromising the WL during treatment.

Keywords: working length determination, minor diameter, electronic apex locator, electronic working length, radiographic working length

\section{Introduction}

A primary objective of endodontic therapy is thorough cleaning and shaping of the entire root canal system to provide an environment that allows healing of periradicular tissues. One of the important steps in achieving this objective is to clean and shape the entire canal system from the orifice to the minor apical foramen. ${ }^{1,2}$ A key factor affecting the success of endodontic treatment is correct determination of root canal working length (WL). ${ }^{3}$ The determination of WL is one of the most important steps in root canal therapy for success. ${ }^{4-6} \mathrm{WL}$ has been defined as "the distance from a coronal reference-point to the point at which canal preparation and obturation should terminate".?

Root canal preparation and filling should not extend beyond the tooth root, nor should leave any uninstrumented areas inside the root canals. ${ }^{8}$ Procedural errors such
Correspondence: Sanjeeb Chaudhary Department of Conservative Dentistry and Endodontics, School of Dental Sciences, Chitwan Medical College, PO Box No. 42, Bharatpur 10, Nepal Tel +977984984965I

Email sanjeebchaudhary@gmail.com 
as over-instrumentation or under-instrumentation can occur because of inaccurate estimation of root canal WL, which may lead to the failure of endodontic treatment. WL must be properly established to prevent over-instrumentation or over-filling of the root canal to support the repair process of the apical tissues. ${ }^{9}$

Over-instrumentation with enlargement of the apical constriction (AC) may cause periradicular inflammation, postoperative pain, and injury to the periapical tissues, thereby delaying or preventing the healing process. ${ }^{10}$ Conversely, under-instrumentation leaves parts of the root canal inappropriately cleaned and shaped, which may lead to less favorable outcome and underfilling of the canal. ${ }^{4-6,11,12}$ Studies have supported that histologic outcomes after endodontic treatment are higher when instrumentations and obturation are limited to AC. ${ }^{6}$ Therefore, accurate determination of the WL is very important for successful endodontic treatment.

A number of methods have been used to determine WL. In clinical practice, radiographs have been the method of choice for WL determination. ${ }^{13}$ The traditional method for determining WL is based on radiographic visualization and interpretation of an instrument placed in the root canal. ${ }^{14}$ The drawback to this method is that the position of the $\mathrm{AC}$ - the most apical portion of the root canal - cannot be determined from a radiograph because of internal morphology of root canals. ${ }^{15,16}$ Dummer et al concluded that it is impossible to locate the AC clinically with certainty because of its position and topography. ${ }^{17}$

The practice of estimating WL by measuring the length of the root from the radiographic apex to the crown and then reducing $0.5-1 \mathrm{~mm}$ has been reported to be unreliable and inaccurate due to distortion of radiographic images. ${ }^{14}$ Pratten and McDonald explained that the assumption of the AC being $1 \mathrm{~mm}$ short of the radiographic apex will result in an underestimation of WL because of the variability in distance between minor foramen and radiographic apex. ${ }^{18}$ Williams et al found that when a file looks short radiographically compared with the radiographic apex, it is actually closer to the major foramen than it appears and vice versa. ${ }^{19}$ Radiographic estimation of the WL has several limitations that can affect correct interpretation making it difficult to accurately determine the WL. ${ }^{15,16,20}$

To overcome the shortcomings associated with radiographs, electronic apex locators (EALs) have been used in endodontics for determining WL. EALs are claimed to precisely locate the position of the minor foramen reducing the error during WL determination. ${ }^{3}$ In recent times, use of EALs has become popular because of their high accuracy rates in locating the AC and has eliminated many of the shortcomings associated with radiographic measurements., ${ }^{3,21-24}$ Their advantages include comparable or better accuracy compared with the radiographic method and they also require a lesser number of radiographs, which reduces radiation exposure as well. ${ }^{25}$ Advances made in EAL technology have also led to the development of EALs that make more accurate readings.

Several studies have shown that current EALs are quite accurate and consistent. . $^{3,13,16,21,23,24,26}$ This has increased their popularity and supported their clinical use. Some studies have shown that EALs provide even more accurate estimation of WL than radiographs. ${ }^{14,16,18,27}$ However, few studies have found that there are no significant differences between the accuracy of EALs and radiographs. ${ }^{28,29}$ Studies also show that false readings are often obtained from EALs indicating the need for radiographic check films. ${ }^{30}$ Therefore, combined use of methods for WL determination is advocated by many.

Custer was the first to introduce the use of electronic devices for WL determination. ${ }^{31}$ Suzuki's $^{32}$ finding led to the development of the first EAL by Sunada. ${ }^{33}$ Since then, different generations (six generations) of EALs have been developed to measure root canal length. The recently introduced fifth generation of EAL also uses multiple frequencies, in addition to calculating the root mean square (RMS) values of the electric signals. The RMS represents the energy of the electric signals, and therefore, it is claimed to be less affected by electrical noises affecting other physical parameters, such as amplitude or phase of electrical signal that are used by other EALs.

Propex II (Dentsply Maillefer, Ballaigues, Switzerland) is a recently developed and newly designed fifth generation EAL. Propex II is a multifrequency-based apex locator that is based on the principle that uses multiple frequencies to determine the root canal length. It measures the capacitance and resistance of the circuit separately. Rather than using the amplitude of the signal, it measures the energy of the signal with multi signal frequencies.

iPex II (NSK Inc., Tochigi, Japan) is also a multifrequency EAL that has been recently introduced. iPex II measures the position of the minor apical diameter by measuring the impedance variation using two different frequencies. By reducing the noise that interferes with signal analysis, it generates a high-precision wave system that does not require a filtering circuit to analyze the extracted frequency. This produces steady measurement analysis even under varying conditions in the root canal while retaining a constant link to file insertion progress. Therefore, Propex II and iPex II have similar mechanisms for WL measurements. 
Generally, only stainless steel (SS) hand files have been used for testing purposes of EALs in various studies. There are few studies that have compared accuracy using both SS and NiTi files at the same time. However, due to widespread use of nickel-titanium (NiTi) files, a comparison of the accuracy in determining length with an EAL using SS and NiTi files seems clinically significant since many clinicians today use both SS and NiTi files during root canal treatment. It is of great significance for the clinician to have confidence in the accuracy of EAL so that these files can be used interchangeably.

Many studies have addressed the benefits and clinical performance of various models of EALs that have been developed in recent years. It has become difficult for the practitioner to choose from the various EALs available due to contrasting claims made by the manufacturer. There have not been many published reports on the correlation of WL obtained using EAL and the radiographic WL. A literature search retrieved few articles comparing the accuracy of EALs using SS Hand K-file and NiTi Hand files but no published study was found that compared the accuracy of Propex II and iPex II in determining the WL using SS Hand K-file and NiTi Hand files to that of radiographic WL. In vivo studies that use EALs to determine the WL simulate the clinical condition in contrast to ex vivo studies where relation to clinical situation might not be suitable.

The purpose of this in vivo study was to compare the accuracy of Propex II and iPex II EAL in determining the WL under clinical conditions, to that of radiographic working length (RWL) using SS hand files and NiTi Hand files.

\section{Patients and methods}

This study was conducted in the Department of Conservative Dentistry and Endodontics, School of Dental Sciences, Chitwan Medical College (Bharatpur, Nepal) with ethical approval from the Institutional Review Committee (Ethical Clearance No: CMC-IRC/2074/075-22). Thirty-seven patients scheduled for nonsurgical endodontic treatment participated in this study. Sixty single canalled anterior teeth (53 incisors and seven canines) with completely formed apices confirmed by periapical radiographs and indicated for endodontic treatment were used in this study. Thus, a total of 60 root canals were available for the study.

A standardized preoperative diagnostic periapical radiograph was taken for each tooth. Patients having teeth with internal or external resorption, curvatures, open apices, root canal obliteration, perforation, incomplete root formation, or radiographically invisible canals were excluded from the study. Pregnant women and patients with pacemakers were also excluded from the study. Informed written consent was obtained from each patient before the treatment, and the patients were informed about routine endodontic procedures.

Local anesthetic was administered (2\% lignocaine with 1:200,000 adrenaline), and access cavity was prepared using high-speed round diamond burs and the canals were identified. The coronal portion of each canal was flared with Protaper SX hand file (Dentsply Maillefer) and the pulp extirpated using a barbed broach. After access cavity preparation, a K-file \# 10 size (Mani Inc., Tochigi, Japan) was passively introduced up to the apical foramen and passed through the apex to verify canal patency. Each root canal was then irrigated with $2.5 \%$ sodium hypochlorite solution and excess removed with an air syringe and cotton pellets without drying the canal. The WL was determined using both the EALs and radiographically.

The electronic working length (EWL) was determined by using the Propex II and iPex II EALs. Both EALs were used according to manufacturers' instructions for EWL determination. The EAL to be used first was selected on a random basis. The lip hook was attached to the patient's lip and an SS hand ISO K-file \# 15 (Mani) with a silicone stop was attached to the file clip of apex locator and advanced apically into the canal. For the ProPex II, the file was advanced into the root canal until the EAL displayed the flashing word "APEX" and " 0.0 " reading along with a solid tone indicating that the apex had been reached (according to the manufacturer's instructions). After removing the file from the canal, the distance (WL) was measured with an SS Boley Gauge ruler caliper to an accuracy of $0.5 \mathrm{~mm}$, and $1 \mathrm{~mm}$ was subtracted from this measurement and recorded. Measurements were considered to be valid if the measurement remained stable for at least 5 seconds. Three measurements were made for each tooth and an average of these measurements was recorded as the EWL. The measurements were then taken with ProTaper S2 (shaping files) (Dentsply Maillefer) NiTi Hand file using ProPex II and measurements recorded similarly.

The same procedure was carried out with SS Hand K-file \# 15 and ProTaper S2 NiTi Hand file using the iPex II and measurements recorded. For the iPex II the file was connected to the EAL and gradually introduced until the EAL bar graph display read 0.0 and a continuous sound tone appeared indicating that the instrument had reached the minor apical diameter. When the signal reached the 0.0 mark (apical foramen), the file was removed and the length measured and $1 \mathrm{~mm}$ was subtracted from this measurement 
and recorded. The same procedure was done using ProTaper S2 NiTi Hand file and measurements recorded.

After determining the EWL, a periapical radiograph with a Hand K-file \#15 within the root canal was taken to determine the RWL as what is usually done in clinical practice. We used average electronic measurements (mean of measurements taken for each tooth) to take radiographs along with preoperative radiograph evaluation for RWL estimation. A size $15 \mathrm{~K}$-file was placed to the estimated length and WL radiograph was taken. Radiographs were examined under magnification, and the distance from the reference point of the file to the radiographic apex was measured and recorded as RWL. All clinical procedures and measurements were performed and recorded by the same operator.

The measurements (millimeter) obtained were tabulated for comparison using the paired sample $t$-test and ANOVA evaluation was conducted at a significance level of $p<0.05$. We used the paired $t$-test to compare the measurements because the same teeth were used. To calculate the agreement of the readings from the EALs with that of radiographic WL, interclass correlation coefficient was calculated. Statistical analysis was performed with Statistical Package for the Social Sciences (SPSS 20.0.0, IBM SPSS Statistics, Inc., Chicago, IL, USA).

\section{Results}

The mean differences between RWL measurements and EWL for ProPex II with SS file was $0.059 \mathrm{~mm}$, ProPex II with NiTi file $0.066 \mathrm{~mm}$, iPex II for SS file $0.059 \mathrm{~mm}$, and iPex II for NiTi files $0.056 \mathrm{~mm}$. Statistical analysis revealed no significant difference $(p>0.05)$ between the means and the standard deviations were similar (Tables 1 and 2), indicating similar accuracies between the EALs with respect to their accuracy in determining the WL $(p>0.05)$. ProPex II and iPex II did not show any statistically significant differences $(p>0.05)$ in their accuracy. No significant difference was found between radiographic and electronic methods as well $(p>0.05)$.

There was no significant difference for both EALs $(p>0.05)$ with SS files when comparing the mean of RWL with EWL of both EALs. Similarly, with NiTi files, no statistically significant difference was noted for both EALs $(p>0.05)$. Paired $t$-test showed no significant differences between SS and NiTi files for the mean difference between RWL and EWL for both EALs ( $p>0.05)$.

Statistical analysis of the correlation of the reading from the EALs and the radiograph were performed by calculating the correlation coefficients (Table 2). Comparing the coincidence between the radiographic and the two electronic measurements, the intraclass correlation coefficient at the 95\% confidence level revealed that the RWL and EWL measurements were coincident in this study. Analysis showed a high intraclass correlation coefficient between the RWL and EWL measurement methods indicating that the radiographic and the EAL measurements were coincident (Table 3).

\section{Discussion}

The objective of this in vivo study was to compare the accuracy of ProPex II and iPex II EALs using SS Hand K-file and NiTi Hand files for determining WL and to compare it

Table I Mean differences and SD between the RWL and EWL measurements of each EAL and file type

\begin{tabular}{lllllllll}
\hline & Mean & SD & $\begin{array}{l}\text { Standard error } \\
\text { mean }\end{array}$ & Lower & Upper & t & df & Significance \\
\hline RWL vs Propex II SS & 0.041 & 0.462 & 0.059 & -0.077 & 0.161 & 0.697 & 59 & 0.488 \\
RWL vs Propex II NiTi & 0.125 & 0.517 & 0.066 & -0.008 & 0.258 & 1.870 & 59 & 0.066 \\
RWL vs Ipex II SS & 0.025 & 0.464 & 0.059 & -0.094 & 0.144 & 0.417 & 59 & 0.678 \\
RWL vs Ipex II NiTi & 0.091 & 0.436 & 0.056 & -0.021 & 0.204 & 1.626 & 59 & 0.109 \\
Propex II SS vs Propex II NiTi & 0.083 & 0.413 & 0.053 & -0.023 & 0.190 & 1.561 & 59 & 0.124 \\
Ipex II SS vs Ipex II NiTi & 0.066 & 0.436 & 0.056 & -0.046 & 0.179 & 1.183 & 59 & 0.241 \\
Propex II SS vs Ipex II SS & -0.016 & 0.431 & 0.055 & -0.128 & 0.094 & -0.299 & 59 & 0.766 \\
Propex II NiTi vs Ipex II NiTi & -0.033 & 0.354 & 0.045 & -0.125 & 0.058 & -0.727 & 59 & 0.470 \\
\hline
\end{tabular}

Abbreviations: $\mathrm{EAL}$, electronic apex locator; $\mathrm{EWL}$, electronic working length; $\mathrm{NiTi}$, nickel-titanium; RWL, radiographic working length; SD, standard deviation; SS, stainless steel.

Table 2 ANOVA analysis

\begin{tabular}{llllll}
\hline & Sum of squares & df & Mean square & $f$ & Significance \\
\hline Between groups & 0.620 & 4 & 0.155 & 0.039 & 0.996 \\
Within groups & $1,150.616$ & 295 & 3.900 & & \\
Total & $1,151.236$ & 299 & & & \\
\hline
\end{tabular}


Table 3 Comparison of the radiographic and the EALs measurements by the intraclass correlation coefficient at $95 \%$ confidence level

\begin{tabular}{llll}
\hline & N & Correlation & Significance \\
\hline RWL vs Propex II SS & 60 & 0.973 & 0.000 \\
RWL vs Propex II NiTi & 60 & 0.967 & 0.000 \\
RWL vs Ipex II SS & 60 & 0.973 & 0.000 \\
RWL vs Ipex II NiTi & 60 & 0.977 & 0.000 \\
\hline
\end{tabular}

Abbreviations: EAL, electronic apex locator; $\mathrm{NiTi}$, nickel-titanium; $\mathrm{RWL}$, radiographic working length; SS, stainless steel.

with RWL. The determination of an accurate WL is one of the most critical steps of endodontic therapy for successful treatment. ${ }^{6}$ The cleaning, shaping, and obturation of the root canal system cannot be accomplished properly unless the WL is determined correctly.

Overestimated WL can lead to over-instrumentation, debris extrusion, and microbial contamination, resulting in pain, overfilling, and infection of the periapical tissues resulting in impairment of healing whereas underestimated WL causes persistence of bacteria and necrotic tissue and underfilling both of which decrease the success rate of endodontic therapy. ${ }^{34}$

Although radiographs are valuable in WL determination and for visualization of pathology and anatomy of the root canal system, they are unreliable in accuracy because they are based on the radiographic apex rather than the minor foramen. ${ }^{14,17,19,35}$ Also, radiographic visualization of the AC or foramen is difficult because these do not always coincide with the radiographic apex. ${ }^{34}$

The use of EALs for WL determination has increased considerably due to their improvements and introduction of the latest generation of EALs, becoming an important adjunct in root canal treatment. ${ }^{13,26}$ In addition, latest generation EALs are considerably less sensitive to the influence of external factors that increase measuring reliability. ${ }^{36,37}$ Several studies have investigated the accuracy and clinical performance of different EALs for WL determination with reported accuracies and efficacy depending on the methods of comparison. ${ }^{24,26}$ Clinical studies provide high-level evidence for reflecting a truly clinical condition. Nonetheless, neither in vitro nor in vivo results can be a true representative of clinical situations. ${ }^{38}$

When determining the WL, the instrument is withdrawn $0.5-1 \mathrm{~mm}$ to prevent overestimation and to ensure that the file tip does not protrude beyond the AC, thereby avoiding root canal over-preparation. ${ }^{13,20,35,39,40} \mathrm{~A}$ point $1 \mathrm{~mm}$ short of the radiographic apex as the RWL and a point $1 \mathrm{~mm}$ short of the " 0.0 " reading on the display of all EALs as EWL was established in this study. There is disagreement among clinicians with respect to the ideal WL for preparation and filling of the root canal, however, and this method is not accepted universally.

The validity of measurements and clinical accuracy of EALs in in vitro studies are questionable. That is why an in vivo model was used in this study. Apical patency was confirmed and preflaring of the coronal portions of canals was done before determining the WL. In order to reduce variables, only one operator carried out the electronic and radiographic WL measurements.

One of the objectives of this in vivo study was to compare the accuracy of Propex II and iPex II to that of the radiographic method of WL determination. A literature search found no in vivo studies comparing the accuracy of the Propex II and iPex II. The study results demonstrated that there was no difference between the EALs and radiographic method in terms of WL determination. The results showed the two methods for WL measurement had no significant difference, disagreeing with some studies that state that EALs are more accurate or superior to radiographs. ${ }^{20,27,29}$ The accuracy of EALs was comparable to radiographs in determining the WL supporting the findings of previous studies in which the results of EWL were similar to RWL with clinically acceptable results. ${ }^{38,41,42}$ As radiographic analysis was used to compare the accuracy of EALs, it is emphasized that the results are related to the radiographic apex and not to the apical foramen.

This study also demonstrated that both the EALs had statistically significant higher correlation with RWL when compared (Table 3). There was no significant difference of Propex II and iPex II in correlation with RWL when compared $(p>0.5)$. Both the EALs revealed that the EWL measurements were reliable and in coincidence with the radiographic measurements.

Our results are in accordance with the previous studies in which the accuracy of EAL for WL determination was quite comparable to RWL measurement as concluded by Ravanshad et al. ${ }^{38}$ An in vitro comparative evaluation of conventional radiography and Root ZX EAL by Javidi et al showed an almost complete correlation with the radiographic method (correlation coefficient $=0.983) \cdot{ }^{43}$ Similarly, an in vivo radiographic evaluation by Paludo et al showed $82 \%$ of values obtained using iPex as acceptable. ${ }^{42}$ Likewise the result of pair-wise comparison showed statistically significant high correlation of EALs with RWL in another study. ${ }^{44}$

Accuracy of Propex II and iPex II EAL in determining the WL was also compared in this in vivo study. Statistical analysis showed no significant differences between the Propex II and iPex II $(p>0.05)$. Under the conditions of this in vivo 
study, both EALs performed equally well with no differences in accuracy between them. A literature search revealed only one in vitro study comparing the accuracy of Propex II and iPex II to corroborate the results of this study. However, the results are in agreement with some studies where either of the EALs was used for comparison.

The accuracy of ProPex II in this study was similar to that reported by Briseño-Marroquín et al in their study who found high precision of Propex II in determination of apical foramen with instrument sizes 08,10 , and 15 , respectively. ${ }^{36}$ The accuracy of the Endex, ProPex II, and Root ZX in locating the apical foramen was $86.1 \%, 83.2 \%$, and $65.3 \%$, respectively, in another study showing high accuracy of ProPex II. ProPex II was more accurate than Root ZX in determining the WL. ${ }^{20}$ Likewise another study found no significant differences between the measurements (93\% for Root ZXII and 90\% for Propex II) when compared to visual method. ${ }^{45}$ In an in vitro study, there were no significant differences between the measurements (Root-ZX 89.7\% and Propex II 82.1\%). Both were able to determine the position of the apical foramen accurately. ${ }^{46}$ Similarly, Somma et al in an in vivo study compared the accuracy of Propex II with Raypex 5, and Dentaport ZX, and found that the differences between the devices were not significant in locating the major foramen. ${ }^{47}$ An in vivo study by Vasconcelos et al also found no differences in accuracy between Root ZX and Propex II with both EALs displaying similar results. ${ }^{48}$

As for the iPex II, an in vitro study revealed no significant difference between the iPex II when compared to other multifrequency EALs, even though the measurement for iPex II was found to be accurate in only $50 \%$ of the specimens. The accuracy of iPex II was similar to those of other multifrequency EALs. ${ }^{49}$ Another in vitro study involving primary teeth in which ProPex II, Raypex 6, and iPex II were tested found similar results for all the EALs concluding that all tested EALs were able to determine WL accurately. ${ }^{50}$

We used SS Hand K-file size \# 15 in the present study. Briseño-Marroquín et al studied the accuracy of four different EALs with three different instrument sizes of hand files and found that sizes 08,10 , and 15 had no influence on the accuracy of WL determination. ${ }^{36}$ Analysis of an ex vivo study by Cianconi et al also showed no significant difference between different instrument sizes of K-files stressing that the performance of EALs was not influenced by instrument sizes of hand files. ${ }^{20}$

During root canal therapy, it is important that various types of files can be used interchangeably without compromise. Under the conditions of this study, we found no significant difference between SS Hand K-file and NiTi file for both the EALs, suggesting both SS Hand K-file and NiTi file are suitable for determining WL and therefore can be used interchangeably without compromising the WL. There were no previous studies to corroborate the results where similar EALs used in this study were evaluated with NiTi files.

Among many studies investigating EALs, few have compared the accuracy of EALs using NiTi files despite its popularity. ${ }^{39,40,51} \mathrm{NiTi}$ files are more flexible and resistant to torsional fracture providing an advantage during the preparation of curved canals. Hence, NiTi files were compared to SS files to evaluate the accuracy of the EALs. The accuracy with SS files in various study ranges from $70 \%-100 \%{ }^{3,22,26,51-53}$ Similarly, the accuracy using NiTi files has been found to be $39 \%-94 \% .^{39,51-53}$

Thomas et al first investigated the effect of type of alloy on the accuracy of EALs using SS files and NiTi files. They found both SS and NiTi files resulted in accurate readings, suggesting these files could be used interchangeably. ${ }^{40}$ In a separate study, EALs with hand files had high accuracies in locating the AC compared with rotary NiTi files in another study; however, the difference was not significant. ${ }^{39}$ The values obtained in this study are in accordance with a recent in vitro study that concludes both SS hand K-file and NiTi hand or rotary files are suitable for determining WL. ${ }^{51,54}$

The findings obtained in this study do not agree with the result of an in vitro study that stated that there was a significant difference between SS and NiTi files for Root ZX and MINI whereas no significant difference was found between SS or NiTi files with ELE and PIXI. ${ }^{53}$ The variations in accuracy were attributed to the principle on which the EAL is based. However, most of the studies have concluded that the type of alloy has no significant effect on accuracy of EALs, which is consistent with the results of this study. ${ }^{40,51,52}$

Dissimilarity in type of study, methods of comparison, interpretation of RWL, type of EAL, reference point for WL, type and size of file, make comparison among studies difficult and also contribute to inconsistency in the study results. The variations of results between this and other studies may be due to differences in operator sensitivity, study design, EALs tested, and radiographic interpretation of WL. The discrepancy may also be due to difference in principles of operation of EALs used in this study. New technologies in EALs make them more accurate, with radiograph being useful only for confirming the EAL readings. The multiple frequency processing technology incorporated into fifth-generation EALs may have been advantageous for increasing the accuracy of the WL measurements. 
The findings of this study suggest EALs are useful for complementing radiographic methods of WL determination and can help in reducing the number of radiographs. The use of EALs does not eliminate the need for radiographic evaluations, which are essential for the diagnosis and evaluation of obturation, as well as postoperative control. ${ }^{55}$ The combined use of radiography and EALs for WL determination provides greater accuracy and also helps to prevent over instrumentation and filling beyond the apical foramen. ${ }^{15,16}$ Therefore, several studies have concluded that the use of a combination of methods to determine WL may be more successful than relying on just one method. ${ }^{30}$ Moreover, differences in canal morphology and medico-legal issues also recommend use of pre- and postoperative radiographs in clinical practice.

Within the limitations of this study, Propex II and iPex II provided clinically acceptable WL values with their accuracy being satisfactory and quite comparable to radiographs. Under the clinical conditions of this study, the overall radiographic and EAL measurements were coincident. The study also showed no difference between SS and NiTi files for WL determination. The results should be interpreted within the limitations of this study and other clinical conditions should be considered for WL determination.

\section{Conclusion}

Both Propex II and iPex II are clinically acceptable apex locators for WL determination and both SS hand K-file and NiTi file can be used interchangeably without compromising the WL during root canal treatment.

\section{Disclosure}

The authors report no conflicts of interest in this work.

\section{References}

1. Vier-Pelisser FV, Meng A, Benedete Netto LC, Só MV. Influence of the instrumentation technique and apical preparation diameter on calcium hydroxide filling in simulated curved canals. Indian J Dent Res. 2012;23(6):784-788.

2. Dinapadu S, Pasari S, Admala SR, Marukala NR, Gurram S, Peddi R. Accuracy of electronic apex locator in enlarged root canals with different root canal irrigants: an in vitro study. J Contemp Dent Pract. 2013;14(4):649-652.

3. D'Assunção FL, de Albuquerque DS, Salazar-Silva JR, de Queiroz Ferreira LC, Bezerra PM. The accuracy of root canal measurements using the Mini Apex Locator and Root ZX-II: an evaluation in vitro. Oral Surg Oral Med Oral Pathol Oral Radiol Endod. 2007;104(3):e50-e53.

4. Ingle JI, Barkland LK. Endodontics. 5th ed. London: BC Decker Inc; 2002:510-512.

5. Ricucci D. Apical limit of root canal instrumentation and obturation, part 1. Literature review. Int Endod J. 1998;31(6):384-393.

6. Ricucci D, Langeland K. Apical limit of root canal instrumentation and obturation, part 2. Histological study. Int Endod J. 1998;31(6):394-409.

7. American Association of Endodontists. Glossary of Endodontic Terms. 9th ed. Chicago: American Association of Endodontists; 2016.
8. Barbizam JVB, Fariniuk LF, Marchesan MA, Pécora JD, Sousa-Neto MD. Effectiveness of manual and rotary instrumentation techniques for cleaning flattened root canals. J Endod. 2002;28(5):365-366.

9. Burch JG, Hulen S. The relationship of the apical foramen to the anatomic apex of the tooth root. Oral Surg Oral Med Oral Pathol. 1972;34(2):262-268.

10. Chugal NM, Clive JM, Spangberg LS. Endodontic infection: some biologic and treatment factors associated with outcome. Oral Sug Oral Med Oral Pathol Oral Radiol Endod. 2003;96(1):81-90.

11. Certosimo FJ, Milos MF, Walker T. Endodontic working length determination - where does it end? Gen Dent. 1999;47(3):281-286; quiz 287-288.

12. Sjögren U, Hagglund B, Sundqvist G, Wing K. Factors affecting the longterm results of endodontic treatment. J Endod. 1990;16(10):498-504.

13. Haffner C, Folwaczny M, Galler K, Hickel R. Accuracy of electronic apex locators in comparison to actual length - an in vivo study. J Dent. 2005;33(8):619-625.

14. Stein TJ, Corcoran JF. Radiographic "working length" revisited. Oral Surg Oral Med Oral Pathol. 1992;74(6):796-800.

15. ElAyouti A, Weiger R, Lost C. Frequency of over instrumentation with an acceptable radiographic working length. J Endod. 2001;27(1):49-52.

16. ElAyouti A, Weiger R, Lost C. The ability of Root ZX apex locator to reduce the frequency of overestimated radiographic working length. J Endod. 2002;28(2):116-119.

17. Dummer PMH, McGinn JH, Rees DG. The position and topography of the apical canal constriction and apical foramen. Int Endod J. 1984;17(4):192-198.

18. Pratten DH, McDonald NJ. Comparison of radiographic and electronic working lengths. J Endod. 1996;22(4):173-176.

19. Williams CB, Joyce AP, Roberts S. A comparison between in vivo radiographic working length determination and measurement after extraction. J Endod. 2006;32(7):624-627.

20. Cianconi L, Angotti V, Felici R, Conte G, Mancini M. Accuracy of three electronic apex locators compared with digital radiography: an ex vivo study. J Endod. 2010;36(12):2003-2007.

21. Kaufman AY, Keila S, Yoshpe M. Accuracy of a new apex locator: an in vitro study. Int Endod J. 2002;35:186-192.

22. Weiger R, John C, Geigle H, Löst C. An in vitro comparison of two modern apex locators. J Endod. 1999;25(11):765-768.

23. Frank AL, Torabinejad M. An in vivo evaluation of Endex electronic apex locator. J Endod. 1993;19(4):177-179.

24. Mayeda DL, Simon JH, Aimar DF, Finley K. In vivo measurement accuracy in vital and necrotic canals with the Endex apex locator. $J$ Endod. 1993;19(11):545-548.

25. Nekoofar MN, Ghandi MM, Hayes SJ, Dummer PMH. The fundamental operating principles of electronic root canal length measurement devices. Int Endod J. 2006;39(8):595-609.

26. Plotino G, Grande NM, Brigante L, Lesti B, Somma F. Ex vivo accuracy of three electronic apex locators: Root ZX, Elements Diagnostic Unit and Apex Locator and ProPex. Int Endod J. 2006;39(5):408-414.

27. Hassanien EE, Hashem A, Chalfin H. Histomorphometric study of the root apex of mandibular premolar teeth: an attempt to correlate working length measured with electronic and radiograph methods to various anatomic positions in the apical portion of the canal. J Endod. 2008;34(4):408-412.

28. Hoer D, Attin T. The accuracy of electronic working length determination. Int Endod J. 2004;37(2):125-131.

29. Vieyra JP, Acosta J. Comparison of working length determination with radiographs and four electronic apex locators. Int Endod J. 2011;44(6):510-518.

30. Kim E, Marmo M, Lee CY, Oh NS, Kim IK. An in vivo comparison of working length determination by only Root-ZX apex locator versus combining Root-ZX apex locator with radiographs using a new impression technique. Oral Surg Oral Med Oral Med Pathol Oral Radiol Endod. 2008;105(4):e79-e83.

31. Custer LE. Exact methods of locating the apical foramen. Q Natl Dent Assoc. 1918;5(8):815-819.

32. Suzuki K. Experimental study on iontophoresis. J Jap Stomatol. $1942 ; 16: 411$. 
33. Sunada I. New method for measuring the length of the root canal. J Dent Res. 1962;41(2):375-387.

34. Vasconcelos BC, Bueno Mde M, Luna-Cruz SM, Duarte MA, Fernandes CA. Accuracy of five electronic foramen locators with different operating systems: an ex vivo study. J Appl Oral Sci. 2013;21(2):132-137.

35. Wrbas KT, Ziegler AA, Altenburger MJ, Schirrmeister JF. In vivo comparison of working length determination with two electronic apex locators. Int Endod J. 2007;40(2):133-138.

36. Briseño-Marroquín B, Frajlich S, Goldberg F, Willershausen BW. Influence of instrument size on the accuracy of different apex locators: an in vitro study. J Endod. 2008;34(6):698-702.

37. Ebraim AK, Yoshioka T, Kobayashi C, Suda H. The effects of file size, sodium hypochlorite and blood in the accuracy of Root ZX apex locator in enlarged root canals: an in vitro study. Aust Dent J. 2006;51(2):153-157.

38. Ravanshad S, Adl A, Anvar J. Effect of working length measurement by electronic apex locator or radiography on the adequacy of final working length: a randomized clinical trial. J Endod. 2010;36(11):1753-1756.

39. Siu C, Marshall JG, Baumgartner JC. An in vivo comparison of the Root ZX II, the Apex NRG XFR, and Mini Apex Locator by using rotary nickel-titanium files. $J$ Endod. 2009;35(7):962-965.

40. Thomas AS, Hartwell GR, Moon PC. The accuracy of the Root ZX electronic apex locator using stainless-steel and nickel-titanium files. J Endod. 2003;29(10):662-663.

41. Koçak S, Koçak MM, Saglam BC. Efficiency of 2 electronic apex locators on working length determination: a clinical study. $J$ Conserv Dent. 2013;16(3):229-232.

42. Paludo L, Souza SL, So MV, Rosa RA, Vier-Pelisser FV, Duarte MA. An in vivo radiographic evaluation of the accuracy of Apex and iPex electronic Apex locators. Braz Dent J. 2012;23(1):54-58.

43. Javidi M, Moradi S, Rashed R, Raziee L. In vitro comparative study of conventional radiography and Root ZX apex locator in determining root canal working length. NY State Dent J. 2009;75(4):48-51.

44. Lekshmy DS, Deepthi PR, Ganesh C, et al. A comparative clinical study on the correlation of working length determined using three different electronic apex locators with radiographic working length: an in vivo study. Endodontology. 2016;28(1):18-22.
45. Miguita KB, Cunha RS, Davini F, Fontana CE, Bueno CES. Comparative analysis of two electronic apexlocators in working length determination at endodontic therapy - an in vitro study. RSBO. 2011;8(1):25-29.

46. Paul R, Paul M, Paul G, Mittal A. Comparison of accuracy of Root ZX and Propex II apex locator: an in-vitro study. Endodontology. 2011;23:22-27.

47. Somma F, Castagnola R, Lajolo C, Paterno Holtzman L, Marigo L. In vivo accuracy of three electronic root canal length measurement devices: Dentaport ZX, Raypex 5 and ProPex II. Int Endod J. 2012;45(6):552-556.

48. Vasconcelos BC, Araujo RBR, Silva FCFA, Luna-Cruz SM, Duarte $\mathrm{MAH}$, Fernandes CAO. In vivo accuracy of two electronic apex locators based on different operation systems. Braz Dent J. 2014;25(1): $12-16$.

49. Gürel M, Helvacıoğlu-Kıvanç B, Ekici A. A comparative assessment of the accuracies of Raypex 5, Raypex 6, Ipex and Ipex II electronic apex locators: an in vitro study. J Istanbul Univ Fac Dent. 2016;51(1): $28-33$.

50. Demiriz L, Kocak MM, Saglam BC, Kocak S. In vitro evaluation of the accuracy of ProPex II, Raypex 6 and iPex II electronic apex locators in primary molar teeth. $J$ Health Res Rev. 2016;3(2):37-40.

51. Sadeghi S, Abolghasemi M. The accuracy of the Raypex 5 electronic apex locator using stainless-steel hand K-file versus nickel-titanium rotary Mtwo file. Med Oral Patol Oral Cir Bucal. 2010;15(5):e788-e790.

52. Nekoofar MH, Sadeghi K, Akha ES, Namazikhah MS. The accuracy of the Neosono Ultima EZ apex locator using files of different alloys: an in vitro study. $J$ Calif Dent Assoc. 2002;30(9):681-684.

53. Gehlot PM, Manjunath V, Manjunath MK. An in vitro evaluation of the accuracy of four electronic apex locators using stainless-steel and nickel-titanium hand files. Restor Dent Endod. 2016;41(1):6-11.

54. Silva EJNL, Herrera DR, Santos CCO, Gomes BPFA, Zaia AA. Accuracy of the Root ZX II using stainless-steel and nickel-titanium files. Dental Press Endod. 2011;1(3):41-44.

55. Martins JN, Marques D, Mata A, Caramês J. Clinical efficacy of electronic apex locators: systematic review. J Endod. 2014;40(6): 759-777.
Clinical, Cosmetic and Investigational Dentistry

\section{Publish your work in this journal}

Clinical, Cosmetic and Investigational Dentistry is an international, peer-reviewed, open access, online journal focusing on the latest clinical and experimental research in dentistry with specific emphasis on cosmetic interventions. Innovative developments in dental materials, techniques and devices that improve outcomes and patient satisfac-

\section{Dovepress}

tion and preference will be highlighted. The manuscript management system is completely online and includes a very quick and fair peerreview system, which is all easy to use. Visit http://www.dovepress. com/testimonials.php to read real quotes from published authors. 